\title{
Research on Adaptive Ant Colony Algorithm in Robot Hole Making Path Planning
}

\author{
Yanmei Liu ${ }^{1}$, Zhen $\mathrm{Chen}^{2}$, Xin Wang ${ }^{1}$, Lei Zhang ${ }^{1}$ and Yongqing $\mathrm{Ji}^{3}$ \\ ${ }^{1}$ College of Automation, Shenyang Aerospace University, Liao Ning, China \\ ${ }^{2}$ Liaoning power transmission and transformation engineering company, Liao \\ Ning, China \\ ${ }^{3}$ China Petroleum Guangxi Petrochemical Industries Co, China \\ 1ymcml@126.com, 2dsbcz@126.com,31154318449@qq.com, \\ ${ }^{4} 2225851853 @ q q . c o m,{ }^{5} 2265349124 @ q q . c o m$
}

\begin{abstract}
With the development of aircraft manufacturing industry robot technology, in the process of modern aircraft manufacturing hole making technology has become more high efficiency, more accurate positioning and more high processing quality. In this paper, the CATIA software is used to build the aircraft component model, Adaptive ant colony algorithm is proposed and applied to the design of robot path planning to get the shortest path between the origin and destination point. Simulation experiment result shows that the size of pheromone volatile factor has a direct influence on the global search ability and convergence speed of the algorithm. So adaptive ant colony algorithm adjusts the dynamic of pheromone volatile factor to improve the non-purpose of the way of making holes, the low path quality, and realizes the optimal path planning of robot hole making.
\end{abstract}

Keywords: CATIA; adaptive ant colony algorithm; robot hole making; path planning

\section{Introduction}

After entering 1990s, the production in aircraft manufacturing industry requirements high quality, high speed and low cost, the aircraft assembly technology has been proposed higher standards. The production of a plane requires of thousands of parts, in which the ratio of riveting and bolting is very large, there are a large number of holes in the work. In the aspect of aircraft assembly holes, the traditional method of making holes usually adopts the model of "line and drill". The process of making holes is artificially controlled, so traditional manual hole drilling technology can't reach requirement in modern aircraft manufacturing industry. With the development of robot technology, its performance has been greatly improved. Because of the large quantities of production and tight time, the positioning accuracy and the quality of the holes making need be also improved. Robot automatic drilling technology has been very mature, and has been widely used in military aircraft and civil aviation aircraft in the production, which has a very important strategic significance and a high military value for each country. However, there is an obvious delay between the advancing technology abroad and the traditional manual drilling in China. The research on automatic hole making system of robot is very backward in China, it is difficult to obtain the competitive advantage in the international competition for the development of aircraft manufacturing industry in China, and robot automatic drilling technology need be studied further.

Path planning algorithm [1]is the most important part in the research field of robot hole making, Of course, path planning is an indispensable part of the robot hole making. Since 90s, automatic hole making equipment has been introduced in china, but the aircraft assembly is still dominated by hand. The development and application of automatic hole 
making technology has reached a high level in the word. In the aspect of aircraft components, the general problem of path planning is in accordance with criteria for evaluation, the robot can safely and efficiently complete the hole making task. There are many kinds of path planning algorithm, and the algorithms can get good effect. At present, many algorithms have been proposed, such as ant colony algorithm, genetic algorithm [2] and particle swarm optimization algorithm and so on, to solve the problem of robot path planning.

Ant colony algorithm [3] is a typical example which uses swarm intelligence to solve practical problems, which was first proposed by the Italian scholar Dorigo 90 years in the 20th century and applied to solve the classic traveling salesman problem. From the ant system, the basic ant colony algorithm has been developed and improved. Ant colony algorithm is a new optimization algorithm, its positive feedback and coordination have good development potential, and it has good adaptability in solving combination optimization problems. Since 1996, the ant colony algorithm was concerned by scholars all over the world, and has been developed rapidly in the field of application. But the traditional ant colony algorithm has many shortcomings, therefore, the improvement of traditional ant colony algorithm is one of the hot spots in the current research direction.

This paper uses software of CATIA [4] to establish a model of aircraft parts, and the data of hole point position are extracted. The planning path is designed by ant colony algorithm, and was compiled in the MATLAB [5] platform. Due to the ant colony algorithm has slow convergence speed of searching the global optimal value ability, so an adaptive algorithm is proposed to dynamically adjust the pheromone volatile factor, through constant iteration, the ant chooses a shortest path by greater probability, to realize robot automatic drilling hole.

\section{Environment Modeling}

Software of CATIA is one of the most powerful aircraft production modeling software. It can provide the working environment for the development of the whole process. Through the establishment of digital development environment, to provide a design and manufacturing process for user, and the simulation of each part to deal with the problem of information exchange. In this paper, the specific design of the path planning based on the adaptive ant colony algorithm in aircraft components is designed for different hole types and get all the holes in CATIA to create process modules, then pick up the hole site of all robot holes in Software of CATIA. As shown in Figure 1.

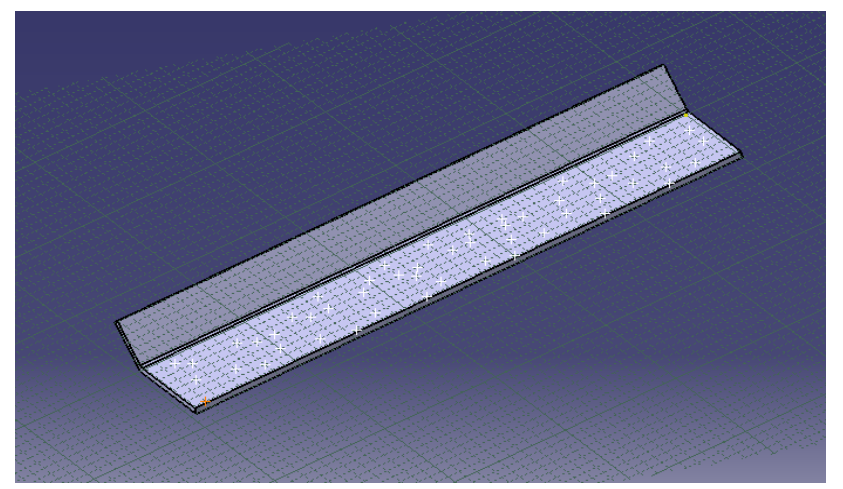

Figure 1. Working Environment Model

\section{Basic Theory of Ant Colony Algorithm}

Ant Colony Optimization is a kind of heuristic hunting arithmetic [6] which applied to combination optimization problems. It possesses positive feedback, distributed calculation and heuristic hunting characters. It is based on the principle 
of ant foraging. The starting point and end point of the ant is represented by two nodes, in the initial stage, the ant colony according to the same probability to choose the path in the absence of prior information. But ants release a volatile secretion on the path (Pheromone, the substance will gradually disappear with time, the size of the pheromone concentration determines the path distance). The amount of pheromone determines the direction of its progress, and it will sense the intensity of the pheromone in the process of looking for food, so the ant chooses the next node from the starting point according to a certain state transition probability, followed by analogy, move to the end finally, Also the more attractive path becomes to be followed by other ants. The probability of other ants selecting the path is increased. The probability of an ant's choice of the current path will change with the volatile and legacy of the pheromone. Because of the constant renewal of pheromone, the ants gradually gathered to the shortest path. A simple model in Figure 2 illustrates how to find food the ant colony through the exchange of information and cooperation, and the process of finding the optimal path between a food source and their nests.
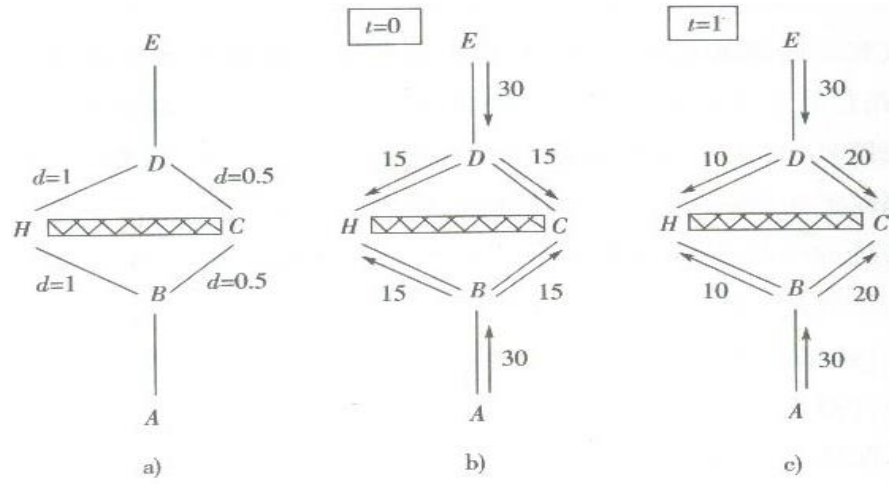

\section{Figure 2. Simulate Ant's Behavior of Looking for Food}

If the ant from A point to $\mathrm{E}$ point. $\mathrm{BH}, \mathrm{HD}$ distance is $1, \mathrm{BC}, \mathrm{CD}$ distance is 0.5 . Suppose that there are 30 ants from A to E, while there are 30 ants from E to A, the speed of ants is set to 1 . At time $t=0$, the pheromone on each path is 0 . The first batch of ants from A is the same as the probability of BCD and BHD, so it can be assumed that the number of ants in the selected path BHD and BCD is 15. Similarly, the ant from $\mathrm{E}$ point to A point, it can be assumed that the number of ants in the selected path DHB and DCB is 15 . At time $t=1$, from $A$ to $E$ the pheromone intensity is 15 in the path $\mathrm{BH}$, that the first batch of 15 ants walk from $\mathrm{H}$ to $\mathrm{D}$ through B. At the same time, it is also found that the pheromone intensity is 30 in path $A B$. Due to intensity of pheromone is very high on path $A B$, the second batch of ants will choose the path according to intensity of pheromone. There will be 20 ants to choose the path $\mathrm{BCD}$ and there are 10 ants to choose the path BHD. In the same way, the second batch from $\mathrm{E}$ to A, there are 20 ants to choose the path DCB and there are 10 ants to choose the path DHB. Through continuous cycle the intensity of pheromone is increasing on the path of BCD and eventually all the ants choose to take this path. As shown in Figure 1, the probability of other ants selecting the path is increased. Ants can also adapt to environmental changes, when there is an obstacle on the path, they will find a new path quickly. This process can be expressed as a loop of positive feedback. Through the positive feedback, ants can find the best path in the end. 


\section{Path Planning for Robot Drilling System Based On Adaptive Ant Colony}

\subsection{Path Planning}

Typical path planning is to find a collision free path from the initial state to the target state in the work environment with obstacles. The robot drilling is related to the accuracy of the hole position, and the path selection of the system which is particularly important. Because of the advantages and disadvantages of path planning directly affect the level of its intelligence, so it is very important to choose a good path planning algorithm for the robot drilling. Undesirably, there are certain limitations in the algorithms applied in the perspective of optimization. The optimization issues, however, are resolved by the ant algorithm brilliantly, which is established and developed since 90s last century. In this paper, an adaptive ant colony algorithm is used to design the path planning to find an optimal path to realize the robot drilling to aircraft parts.

\subsection{Adaptive Ant Colony Algorithm}

The main basis of ant colony algorithm is the combination of the principle of information positive feedback and heuristic search algorithm. In optimization stage, the algorithm should have stronger ability of global searching and rapidly converging; and during stagnation stage, the algorithm should can automatically jump out of local optimal solution and continue to search the global optimal solution. To avoid premature to fall into local optimal solution and blind search, the algorithm requires randomness of search and accuracy of solution. In order to overcome defects of ACO, the basic idea of adaptive ant colony algorithm is described in Wang Ying's paper [7] of lead-in adaptive adjustment strategy based on ant colony algorithm. The size of the pheromone volatile factor is directly related to the global search ability or the local search ability and the convergence rate. A variety of strategies to update the pheromone volatile factor were proposed in the references quoted [8]. In order to improve the ability of global search and prevent the early converging, and the change of the value of the volatile factor in ant colony algorithm is proposed. In order to overcome defects of ACO, in this paper an adaptive ant colony algorithm is presented.

\subsection{Path Planning for Robot Drilling Base on Adaptive Ant Colony Algorithm}

The flow of the path planning based on adaptive ant colony algorithm is followed:

1) Adaptive Ant Algorithm for Initializing

At the beginning of the algorithm, assuming the pheromone concentration is equal in each path. Suppose that there are $\mathrm{m}$ ants placed in separate $\mathrm{N}$ hole position; Counter for cycle times $\mathrm{NC}=0$, max algebra is $N C_{\max }$; initial value of pheromone intensity $\tau_{i j}(\mathbf{O})=\mathbf{O}$.

Through the list tabe $_{k}$ achieving $\mathrm{m}$ ants placed in separate $\mathrm{N}$ hole position during each cycle, and recording every round of ant $\mathrm{K}$ going through each hole position, in $\mathrm{k}=(1,2,3 ., \mathrm{m})$. Before $\mathrm{t}$ time, the location of all the holes in the list is stored in the list. At the same time, the list covers the order of each ant through the hole points and calculates the total path length of each ant in this cycle, and finally gets the current solution of the algorithm optimization. 
2) Selecting the next hole location

At time $\mathrm{t}=0$, the probability of the ant $\mathrm{K}$ from point $\mathrm{I}$ to point $\mathrm{J}$ is related to visibility and pheromone. The probability of the ant $\mathrm{k}$ moving from the hole point $\mathrm{i}$ to $\mathrm{j}$ is defined as followed:

$$
p_{i j}^{k}= \begin{cases}\frac{\tau_{i j}^{\alpha}(t) \cdot \eta_{i j}^{\beta}(t)}{\sum_{s \in a / l \text { oned }_{k}} \tau_{i s}^{\alpha}(t) \cdot \eta_{i s}^{\beta}(t)} & j \in J_{k}(i) \\ 0 & j \notin J_{k}(i)\end{cases}
$$

where, $P_{i j}^{k}(t)$ denotes the transition probability in which the ant $\mathrm{k}$ from path $\mathrm{i}$ to $\mathrm{j}$ at time $\mathrm{t} ; \tau_{\mathrm{ij}}(\mathrm{t})$ is the intensity of the pheromone between path $\mathrm{i}$ and $\mathrm{j}$ at time $\mathrm{t} ; \eta_{\mathrm{ij}}(\mathrm{t})$ represents the heuristic function between path $\mathrm{i}$ and $\mathrm{j}$, and $\eta_{i j}=1 / d_{i j}$ is the reciprocal distance between the hole I and hole $\mathrm{J} ; \alpha$ is information inspiration factor. the relative importance of residual pheromone on the path is indicated, and its value reflects the role of stochastic factors in the path search; $\beta$ is hope inspiration factor, and the importance of visibility of the path is indicated, and the role of the ant colony in the path search is determined by its value responsed; $\boldsymbol{J}_{k}(i)$ shows the ant $\mathrm{K}$ has no access to a set of points of the system that is not visited before making the

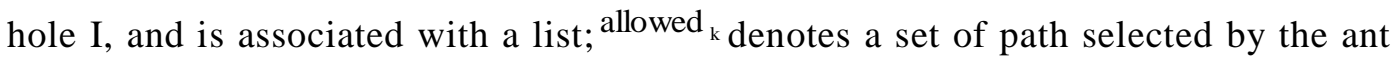
kin next node.

3) Adaptive Control Strategy of Volatile Factor for Adaptive Ant Colony Algorithm

In the ant colony algorithm, pheromone volatilization factor is put out as a measure of pheromone evaporation rate parameters proposed, and its size has a direct influence on the algorithm execution time, global search ability and convergence speed. Traditional ant algorithm in the process of searching does many iterations, and each iteration is the need a lot of ants together to search, so that the convergence rate of the algorithm is reduced. The algorithm is larger when dealing with the problem that may occur rarely or never is visited by some of the route. The reason that leads to the decrease of the global search ability of the algorithm is that the pheromone is constantly volatile and is reduced to 0 , which is no longer being searched. Normally, the initial value of the range of 0.1-0.9, in the specific application can be adjusted according to the actual situation or after trial. The relationship between volatile factor and path length is shown in Figure 3.

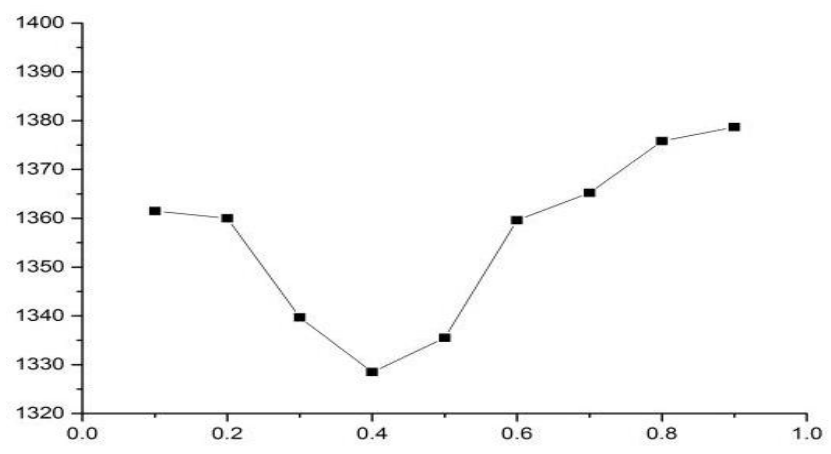

Figure 3. Relationship between Volatile Factor and Path Length

In Figure 3, volatile factor value is relatively idealin the [0.1-0.6] range. The path length is the most ideal when the value is 0.4 and 0.5 , and the results obtained in the 0.8 and 0.9 are not so ideal, so initially bound to false $\rho=0.4$ is set. Experimental results can be seen by changing the value of volatile factors to achieve the optimal 
path. If $\rho$ is too small, ACO is prone to local convergence. On the contrary, $\rho_{\text {is too }}$ large, although it can improved ACO random search performance and global search capability, the convergence rate of the algorithm will be reduced. To solve above problem, an adaptive ant colony algorithm is proposed to improve the convergence speed of the traditional ant colony algorithm and the ability of searching the global optimal solution, and the appropriate change of pheromone volatile factor. Expression as:

$$
\rho(t)= \begin{cases}0.95(\rho-t) & \rho \leq 0.5 \\ 0.5 & \rho>0.5\end{cases}
$$

Updating Pheromone

Information is an important basis for path selection. At time t, each ant chooses the hole point according to the transition probability, and reach the end point in $t+1$ time. The pheromone will be updated on the path $(\mathrm{i}, \mathrm{j})$, which can be show as follows:

$$
\tau_{i j}(t+n)=\rho \tau_{i j}(t)+\Delta \tau_{i j}=\rho \tau_{i j}+\sum_{k=1}^{m} \Delta \tau_{i j}^{k}
$$

Where, $\rho \in(0,1)$ is the pheromone evaporation factor, and show the volatilization process of pheromone trails; ${ }^{1-\rho}$ represents volatilization of pheromone in turn loop; $\tau_{\mathrm{ij}}(\mathrm{t})$ is the intensity of the pheromone between path $\mathrm{i}$ and $\mathrm{j}$ at time $\mathrm{t}$; $\Delta \tau_{i j}$ is pheromone amount of the unit length of all ants in the path; $\Delta \tau_{i j}^{k}$ is the k ant to stay on the path of the amount of information per unit length in time $(t, t+n)$.

Scholars have proposed several different pheromone update models, there are three mainly models [9], Ant-Cycle model, Ant-Quantity model and Ant-Density model. After an ant completes an iteration, the optimization pheromone is updated on all paths according to the global whole path. The paper chooses Ant-Cycle model, which can be ex-pressed as follows:

$$
\Delta \tau_{i j}^{k}=\left\{\begin{array}{c}
\frac{Q}{L_{k}}, \text { when the } k \text { ant through the path }(i, j) \text { in this circle } \\
0,
\end{array}\right.
$$

Where, Q is a constant of pheromone; ${ }^{L_{k}}$ is the length of path passed by the ant $\mathrm{k}$. From (2) and(3), it can be seen that the pheromone intensity of a certain path (I, J) is determined by the intensity of the pheromone $\tau_{i j}(t)$ and the accumulation of pheromone $\Delta \tau_{i j}$ during the cycle. In the course of this cycle, if a lot of ants passing through this path, then left the large amount of pheromone, ants walk through the path of the shorter and the contribution of pheromone intensity is great.

The number of iteration to achieve the optimal solution meeting the demand is determined and is used as the termination condition of the algorithm. OtherwiseNC $=\mathrm{NC}+1$, and loop executes Step 2 to 4 until the optimal solution.

Adaptive ant colony algorithm improves the performance of the traditional algorithm. Traditional ant colony algorithm in the process of global search, the pheromone that the ant leaves behind will slowly disappear with the scope of the search element and makes the global search ability of the algorithm reduce. Adaptive ant colony algorithm by changing the pheromone volatile factor strategy accelerates the convergence speed and enhances the global searching ability, to achieve a shortest path. 


\section{Simulation Result}

In order to test the usefulness and high effectiveness of the adaptive ant colony algorithm, the simulation experiment of the path planning was designed and realizedfor the robot drilling hole in this paper. The main parameters were set. Number of ant colony $m=100$;information inspiration factor $\alpha=2$; hope inspiration factor $B=3$; constant $Q=1$; number of iterations $\mathrm{NC}=500$. Adaptive ant colony path planning algorithm was designed in this paper, and simulated in Matlab 7.1 platform to compare traditional ant colony algorithm and adaptive ant colony algorithm. It is proved that the improved ant colony algorithm has better search optimal solution than traditional ant colony algorithm. As shown in Figure 4, most ants choose a path to the destination, which is the optimal path that can be found in the work environment model to complete a shortest path for the robot to drilling holes $[10,11]$.

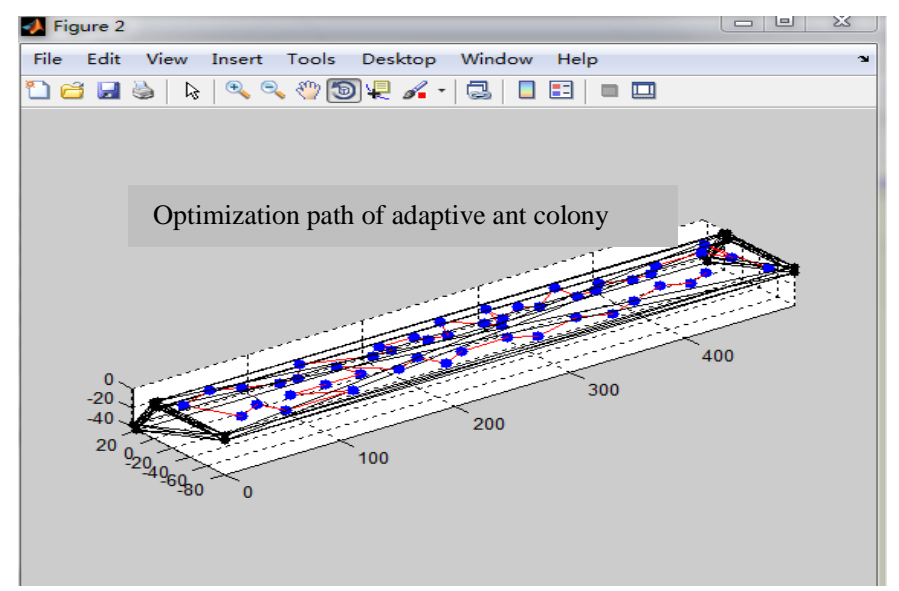

Figure 4. Optimization Path of Adaptive Ant Colony

From Figure 4 , it can be seen that $\rho$ and $\rho_{\text {value directly affect the convergence }}$ and search ability. The adaptive ant colony algorithm is improved in the optimal solution and the path length. The convergence of adaptive ant colony algorithm and basic ant colony algorithm are compared and analyzed by simulation in Figure 5 and Figure 6.

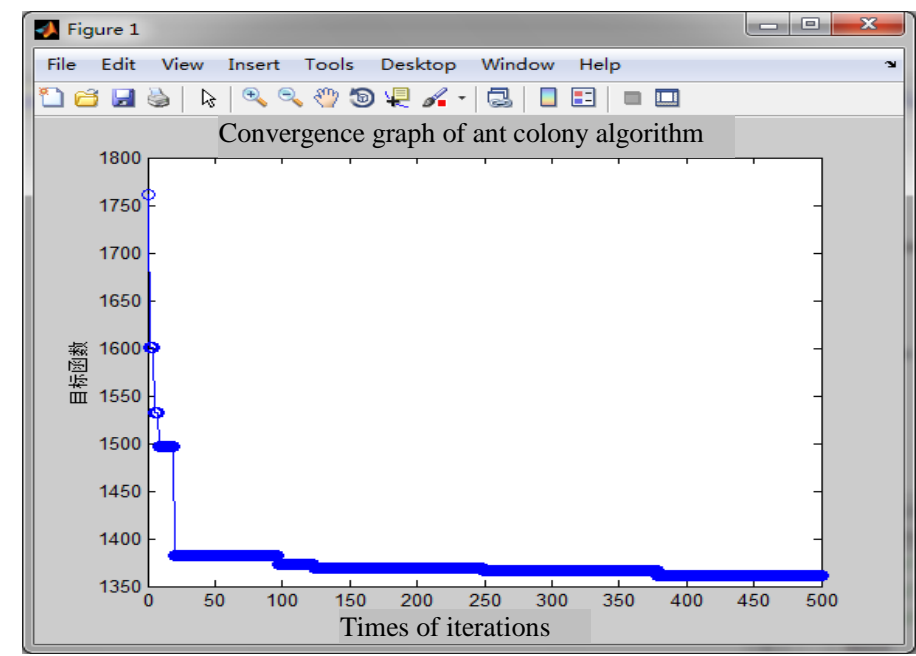

Figure 5. Convergence Graph of Ant Colony Algorithm 


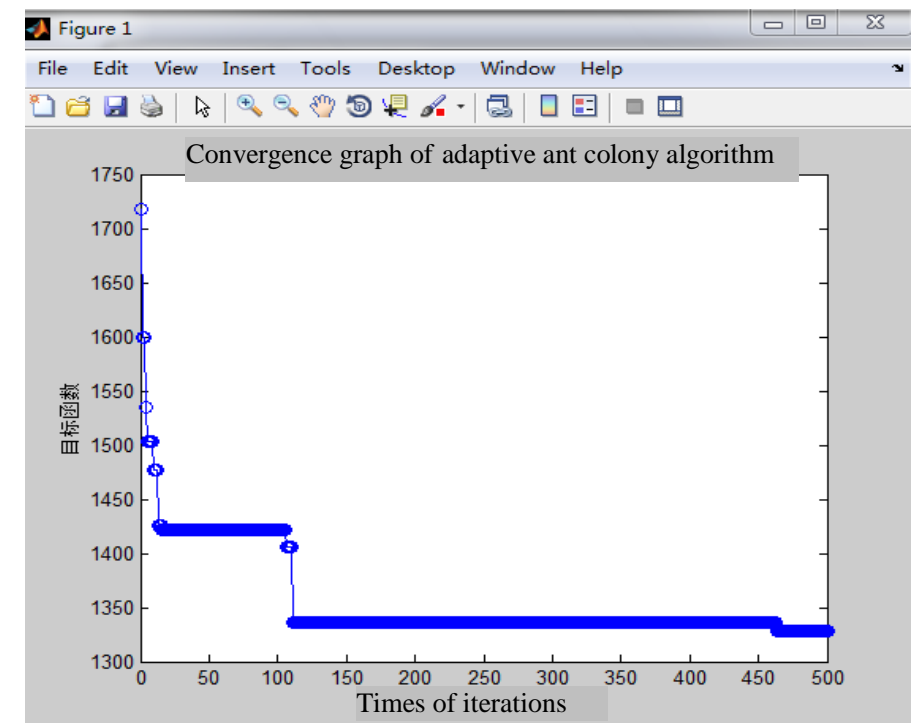

\section{Figure 6. Convergence Graph of Adaptive Ant Colony Algorithm}

The convergence curves of the traditional algorithm and the adaptive algorithm are obtained by the simulation results. From Figure 5 and Figure 6, it can be seen that the shortest path length of the robot path planning based on the traditional ant colony algorithm is 1360.7960 , while the shortest path length of the robot path planning based on the adaptive ant colony algorithm is 1328.5121 . From the point of view of computing time and path planning, adaptive ant colony algorithm for path planning of robot has faster convergence speed, and full path length is shorter, that is obviously superior to the traditional ant colony planning method, and solves the problem of global searching ability and slow convergence speed.

\section{Conclusion}

Aiming at the disadvantages of the basic ant colony algorithm, in this paper adaptive ant colony algorithm is proposed for path planning, so that the traditional ant colony algorithm is more easy to search target, which improves the convergence rate of the algorithm and the ability to search the global optimal value in search process. From the time and space, the characteristics of convergence and searching ability are improved. The adaptive ant colony algorithm overcomes the shortcomings of the traditional ant colony algorithm, and provides guidance for path planning of robot drilling hole. The simulation results can be seen, the adaptive ant colony algorithm proposed gets an optimal path, and achieves very good results. Software of CATIA for 3D modeling of aircraft parts can extract the hole point coordinates required and a starting point and ending point given. Adaptive ant colony algorithm is programmed in the MATLAB platform, and get an optimal path for the design of the components to carry on the robot drilling hole.

\section{Acknowledgments}

Firstly, this work was financially supported by the National Natural Science Foundation of China (61203352) and Aeronautical Science Foundation of China(2015ZE54026). Secondly, thanks my teachers for guidance to my research, I have received new study skills and methods from them, which will have a significant impact on my future research. Meanwhile thanks my classmates and friends who help me. Finally, thanks expert reviewers' advice and guidance to my paper. 


\section{References}

[1] Y. Zhang, A. Zhang and Z. Zhang, "Tactical Flight Path Planning Algorithm”, Journal of traffic and Transportation Engineering, vol. 12, no. 7, (2006), pp. 84-87.

[2] J. Yang, B. Hong and S. Piao, "Local Obstacle Avoidance Planning for Robots Based on Genetic Fuzzy Algorithm", Journal of Harbin Institute of Technology, vol. 36, no. 7, (2004), pp. 946-948.

[3] T. Guanzheng, H. Huan and A. Sloman, "Ant Colony System Algorithm for Real-time Globally Optimal Path Planning of Mobile Robots", Automatics Sinica, vol. 33, no. 3, (2007), pp. 279-285.

[4] C. Qi and S. Wang, "CATIA V5 R21 3D Digital Modeling And Dynamic Simulation Basic Course", Beijing:Tsinghua University Press, (2013).

[5] D. Zhang, "Design of MATLAB Automatic Control System", Beijing:Machinery Industry Press, (2010).

[6] X. Peng and Y. Peng, "Applications and Theory of Swarm Intelligence", Journal of Electronics, vol. 31, no. 12 , (2003), pp. 35-37.

[7] Y. Wang and J. Xie, "Simulation Research of An Adaptive Ant Colony Algorithm", Journal of System Simulation, vol. 14, no. 1, (2002), pp. 31-33.

[8] L. Zhou, "Application of adaptive ant colony algorithm in 3D path planning of wheeled robot", Mechanical Science And Technology, vol. 32, no. 1, (2013), pp. 65-68.

[9] L. Yanjun and W. Tiejun, "Anadaptive ant colony system algorithm for continuous-space optimization problems", Journal of Zhejiang University Science, vol. 4, no. 1, (2003), pp. 40-46.

[10] Z. Han and W. Guo, "Research on the Path Planning of Automatic Drilling Hole Assembly for Aircraft Assembly Based on MBD”, Mechanical Design and Manufacture, vol. 10, no. 10, (2015), pp. 201-203.

[11] S. Li, "Application of the Ant Colony Algorithm", Harbin, Harbin Institute of Technology Press, (2013).

\section{Authors}

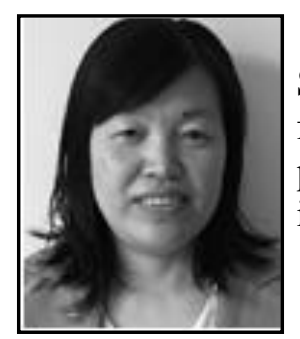

Yanmei Liu, Born in 1974, she received master degree from Shenyang University of Technology in 2003 and doctor degree from Northeastern University in 2006. Now she is an associate professor in Shenyang Aerospace University. Her main research interests are Pattern Recognition and Intelligent Systems.

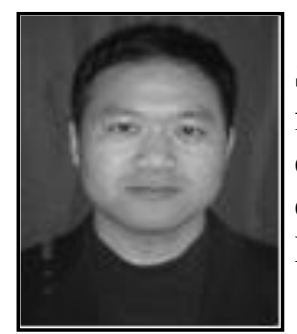

Zhen Chen, Born in 1976, he received master degree from Shenyang University of Technology in 2006 and doctor degree from Northeastern University in 2013. Now he is a senior engineer in Liaoning power transmission and transformation engineering company. His main research interests are Pattern Recognition and Intelligent Systems 
International Journal of Control and Automation

Vol. 10, No. 5 (2017) 